\title{
ONE REFINEMENT OF JENSEN'S DISCRETE INEQUALITY AND APPLICATIONS
}

\author{
V. ČULJAK AND B. IVANKOVIĆ \\ Abstract. Jensen's inequality induces different forms of functionals which enables refinements \\ for many classic inequalities ([5]). Several refinements of Jensen's inequalities were given in [4]. \\ In this paper we refine Jensen's inequality by separating a discrete domain of it. At the end, we \\ give some applications.
}

Mathematics subject classification (2000): 26D15.

Keywords and phrases: Jensen's inequality; convex functions; linear spaces; AG-inequality.

\section{REFERENCES}

[1] J. E. PeČArić, F. Proschan, Y. L. Tong, Convex functions, partial orderings, and statistical applications, Mathematics in science and engineering, Georgia Institute of Tehnology, 1992.

[2] G.H. Hardy, J. E. Littlewood and G. Pólya, Inequalities, Cambridge, 1934.

[3] S.S. DRAGOMIR, A refinement of Jensen's inequality with applications for $f$-divergence measures, JIPAM, J. Inequal. Pure Appl. Math., 10 (2007), article 15. (electronic)

[4] N.S. BARNET AND S.S. DRAGOMIR, On some inequalities for convex functions with applications in normed spaces, MIA, Mathematical Inequalities and Applications, preprint, 2008.

[5] S.S. Dragomir, J. PeČARIĆ AND L.E. PERSSOn, Properties of some functionals related to Jensen's inequality, Acta Math. Hungarica, 70, 1-2 (1996), 129-143. 